\title{
STUDI FAKTOR PENYEBAB KETERLAMBATAN PROYEK KONSTRUKSI STUDI KASUS PROYEK PEMBANGUNAN 6 RUAS JALAN TOL DALAM KOTA JAKARTA
}

\author{
oleh : \\ Andi Maddeppungeng \\ Teknik Sipil Universitas Sultan Ageng Tirtayasa \\ Email : andi_made@yahoo.com \\ Dwi Esti Intari \\ Teknik Sipil Universitas Sultan Ageng Tirtayasa \\ Email : dwiesti@untirta.ac.id \\ Aulia Oktafiani \\ Teknik Sipil Universitas Sultan Ageng Tirtayasa \\ Email : auliaoktafiani90@gmail.com
}

\begin{abstract}
Abstrak: Keterlambatan dalam proyek konstruksi merupakan masalah fenomena global. Di Indonesia, keterlambatan ini menjadi masalah klasik yang sering terjadi di setiap proyek konstruksi. Pada pelaksanaan proyek konstruksi sering mengalami kendala pada proses pekerjaan. Kendala tersebut menjadi penyebab terlambatnya pelaksanaan proyek, sehingga proyek tersebut tidak berlangsung sesuai rencana. Dikarenakan banyaknya indikator-indikator yang dapat mempengaruhi keterlambatan pekerjaan pada proyek pembangunan 6 Ruas Jalan Tol dalam Kota Jakarta, maka penelitian ini bertujuan untuk mencari 10 faktor utama yang mempengaruhi terlambatnya pembangunan proyek tersebut dengan menganalisis menggunakan Metode Rangking. Penelitian ini dilakukan dengan cara penyebaran kuesioner sebanyak 50 variabel yang diajukan kepada 50 responden di perusahaan kontraktor. Dan diolah menggunakan software SPSS v.25 untuk melakukan uji validitas, uji reliabilitas, dan uji korelasi. Untuk uji peringat digunakan metode analisis deskriptif atau mencari nilai rata-rata yang bertujuan untuk menentukan variabel yang memiliki faktor dari yang tertinggi hingga terendah. Berdasarkan hasil penelitian, setelah dilakukan uji validitas didapatkan 2 dari 50 variabel "Tidak Valid". Dengan nilai Cronbach Alpha yang didapat dari uji reliabilitas adalah 0.951 yang berarti memiliki reliabilitas tinggi atau memiliki tingkat konsisten yang tinggi yang apabila dilakukan analisis pada waktu yang berbeda maka hasilnya akan tetap sama. Untuk variabel dengan peringkat tertinggi adalah variabel X6 (Kurangnya keahlian tenaga kerja).
\end{abstract}

Kata Kunci : Jalan Tol layang, SPSS V.25, Faktor-Faktor Keterlambatan, Analisis Rangking

Abstract : Delay in construction projects is a matter of global phenomenon. In Indonesia, this delay is a classic problem that often occurs in every construction project. In the implementation of construction projects often experience obstacles in the work process. These constraints caused the delay in the implementation of the project, so the project did not proceed according to plan. Due to the large number of indicators that can affect work delays in construction projects 6 Toll Roads in the City of Jakarta, this study aims to find 10 main factors that influence the delay in project development by analyzing using the Ranking Method. This research was conducted by distributing questionnaires as many as 50 variables submitted to 50 respondents in the contracting company. And processed using SPSS v.25 software to conduct validity, reliability, and correlation tests. For the warning test used descriptive analysis method or look for the average value which aims to determine the variables that have factors from highest to lowest. 
Based on the results of the study, after testing the validity obtained 2 of 50 variables "Invalid". With the Cronbach Alpha value obtained from the reliability test is 0.951 which means it has a high relia bility or has a high level of consistency which, if analyzed at different times, the results will remain the same. For the variable with the highest rank is variable X6 (Lack of expertise in labor).

Keywords : Overpass, SPSS V.25, Delay Factors, Rangking Analysis

\section{Pendahuluan}

Pembangunan merupakan suatu bukti kemajuan suatu bangsa. Bangsa Indonesia kini sedang giat melaksanakan pembangunan untuk memajukan kesejahteraan masyarakat, karena itu pembangunan harus berjalan dengan baik dan dapat dinikmati oleh seluruh masyarakat guna mensejahterakan dan memakmurkan kehidupan masyarakat. Jakarta merupakan salah satu kota yang terus berkembang tingkat pembangunannya, salah satunya proyek pembangunan 6 Ruas Jalan Tol dalam Kota Jakarta. Pada pelaksanaan proyek konstruksi sering mengalami kendala pada proses pekerjaan. Kendala tersebut menjadi penyebab terlambatnya pelaksanaan proyek, sehingga proyek tersebut tidak berlangsung sesuai rencana. Dikarenakan banyaknya kasus keterlambatan pelaksanaan konstruksi, maka pada penelitian ini akan diadakan studi faktor penyebab terjadinya keterlambatan dengan metode analisis deskriptif dengan cara mencari nilai rata-rata.

\section{Rumusan Masalah}

a. Faktor-faktor apa saja yang menyebabkan keterlambatan pekerjaan pada proyek Pembangunan 6 Ruas Jalan Tol dalam Kota Jakarta?

b. Bagaimana cara mengantisipasi dan memberikan solusi dari masalah dengan memproses dan menyimpulkan data yang didapat?

\section{Tujuan Penelitian}

a. Untuk mengetahui 10 faktor yang paling berpengaruh terhadap keterlambatan penyelesaian pada Proyek Pembangunan 6 Ruas Jalan Tol dalam Kota.

b. Untuk mengetahui cara mengantisipasi dan solusi masalah keterlambatan dengan memproses dan menyimpulkan data yang didapat.

\section{Lokasi Penelitian}

Lokasi penelitian adalah proyek pembangunan Jalan Tol dalam Kota Jakarta.

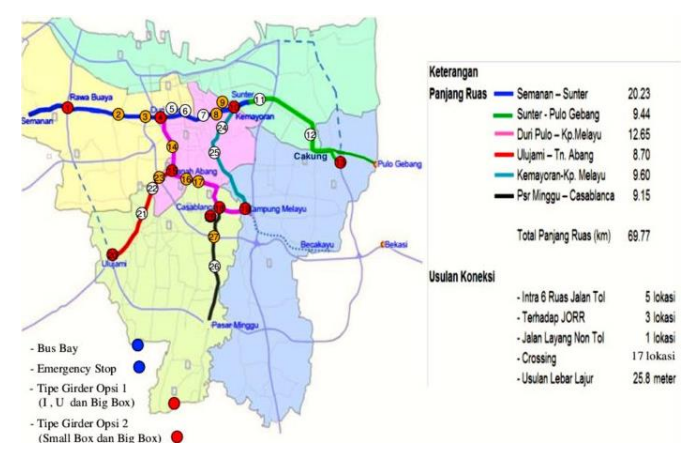

Gambar 1. Lokasi penelitian

Sumber : Data Proyek 6 Ruas Jalan Tol Dalam Kota Jakarta

\section{Kerangka Konseptual}

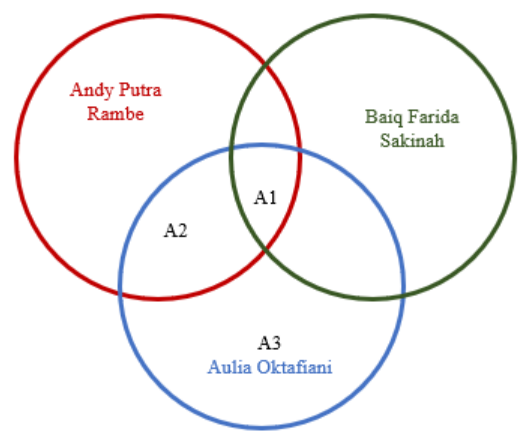

Gambar 2. Kerangka Konseptual

Sumber: Analisis Penulis, 2019 
Analisis Penyebab Keterlambatan Pada Pekerjaan Konstruksi Jalan Kabupaten Lombok Tengah Dengan Metode Analisis Faktor

Penelitian Baiq Farida Sakinah (2015) tentang "Analisis Penyebab Keterlambatan Pada Pekerjaan Konstruksi Jalan Kabupaten Lombok Tengah Dengan Metode Analisis Faktor" [4] mempelajari faktor penyebab keterlambatan di proyek konstruksi dengan menggunakan 2 metode yaitu metode relatif indeks dan metode analisis faktor. Ada 3 faktor yang menjadi penyebab kecelakaan pada metode relatif indeks yaitu pengadaan alat konstruksi yang tidak termanajemen, intervensi negatif dari masyarakat, dan perubahan kondisi lapangan. Sedangkan untuk metode analisis terdapat dua faktor seperti faktor manusia, peralatan, manajemen, dan organisasi.

\section{Analisis Faktor Penyebab Keterlambatan Proyek Konstruksi Jalan Tol}

Penelitian Andy Putra Rambe (2018) tentang "Faktor yang dapat mempengaruhi keterlambatan penyelesaian proyek konstruksi jalan di Lingkungan kabupatek Lombok Tengah" [2] membahas beberapa faktor penyebab keterlambatan diantaranya adalah jurangnya jumlah tenaga kerja dilapagan, terjadi sengketa lahan, sulitnya pembebasan lahan oleh masyarakat,keamanan kerja dilapangan yang kurang terjamin. Dan faktor utama adalah sulitnya pembebaasan lahan oleh masyarakat dari aspek lain.

\section{Metodologi Penelitian}

Penelitian ini dilakuakan dengan tujuan untuk mengidentifikasi faktor keterlambatan dengan menggunakan varibel-variabel yang telah divalidasi. Penelitian ini adalah penelitian kuantitatif yang bersifat deskriptif dimana pengumpulan data dilakukan dengan cara survey melalui angket atau kuesioner dan wawancara analisis tindak lanjut kepada responden. Ada beberapa jenis pendekatan kuantitatif dalam penelitian ini menggunakan pendekatan kuantitatif deskriptif analitik penelitian jenis ini menggunakan metode statistika mulai dari yang sederhana hingga penelitian menggunakan statistika uji yang lebih kompleks (Deni Darmawan , 2014)

"Pengumpulan data dilakukan dengan kuesioner, menggunakan instrument yang telah disusun. Obyek penelitian adalah suatu hal atau apa saja yang menjadi perhatian dan apa saja yang di teliti dalam penelitian (Kamus Bahasa Indonesia, 1994)" [6].

Penelitian ini menggunakan metode Mean Rank yaitu mencari nilai rata-rata untuk mengurutkan menjadi peringkat dari yang tertinggi sampai terendah.

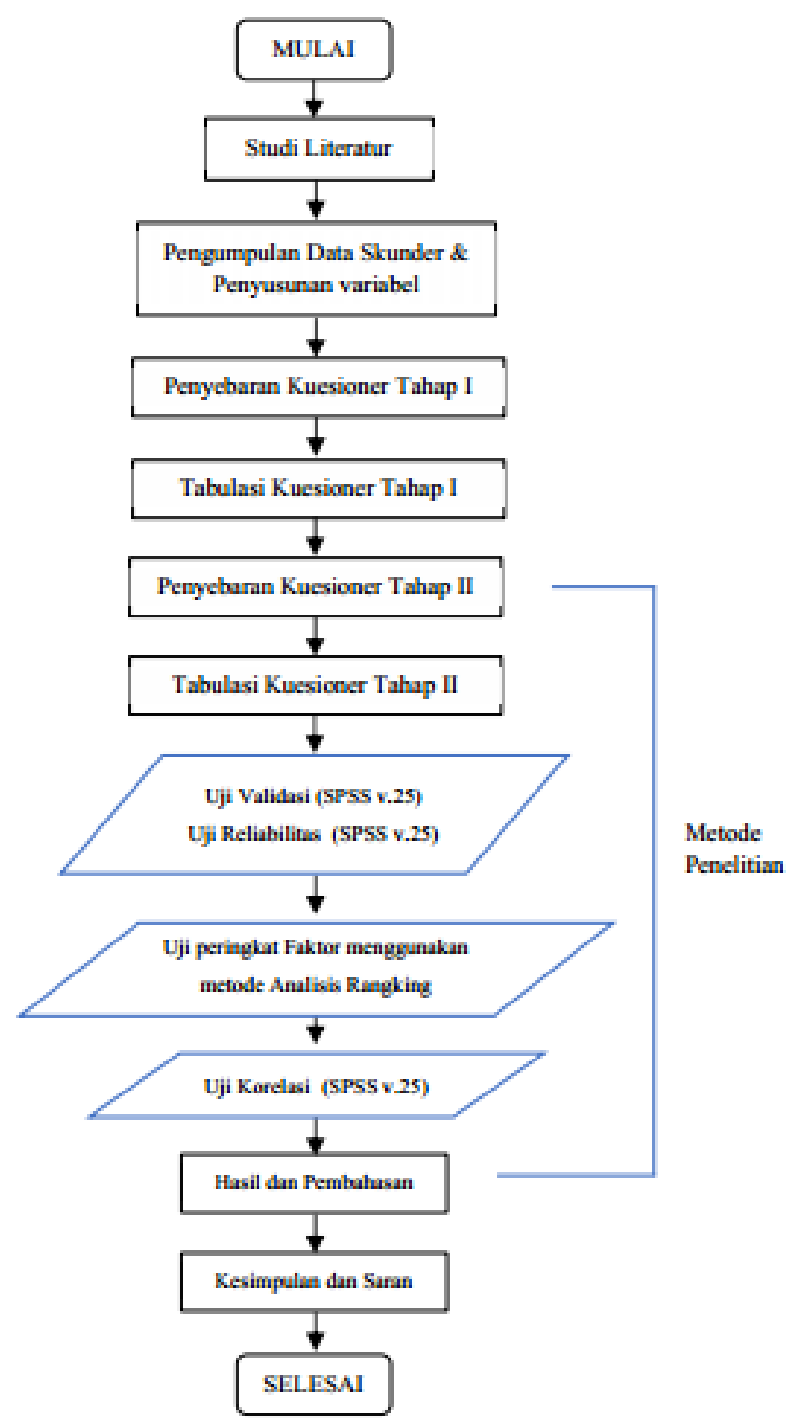

Gambar 3. Diagram alir penelitian

Sumber: Analisis Penulis, 2019 
a. Kajian pendahuluan

b. Perumusan masalah dan Tujuan Penelitian

c. Studi Literatur

d. Pengumpulan populasi dan sampel penelitian

e. Identifikasi variabel

f. Survey

1) Kuesioner Tahap I (divalidasi oleh pakar)

2) Kuesioner Tahap II (disebarkan pada sejumlah staf yang berkaitan dengan keterlambatan proyek)

j. Tabulasi Data

1) Uji Validitas dan Uji Reliabilitas

Untuk menguji instrumen penelitian berupa variable, diperlukan instrument yang valid dan reliabel. Validitas menunjukan ketepatan dan kecermatan alat ukur dalam melakukan fungsi ukurnya. Reliabilitas menunjukan hasil pengukuran konsisten walau digunakan mengukur berkali-kali. Pengujian ini menggunakan SPSS v.25

2) Analisis Perigkat

Data yang telah didapatkan dari hasil pengisian kuesioner menggunakan skala Likert kemudian ditabulasi untuk mencari nilai rata-rata. Hasil akhir perhitungan ini merupakan urutan peringkat berdasarkan bobot. Pada pengujian ini dilakukan dengan bantuan Ms. Excel.

3) Uji Korelasi

Fitri et.al (2012) metode analisis korelasi spearman berguna untuk mengetahui hubungan antara variabel bebas dan variabel terikat yang mengandung unsur pemeringkatan atau terkait dengan urutan data

k. Hasil dan Pembahasan.

l. Kesimpulan dan saran

Kesimpulan dan saran merupakan hasil akhir dari keseluruhan proses penelitian dan segala kekurangan dan keterbatasan dalam penelitian ini dapat dijadikan masukan untuk penelitian berikutnya

\section{Analisis Dan Pembahasan}

Dilakukan dengan 2 tahap yaitu penyebaran kuesioner kepada para pakar untuk dilakukan validasi. Selanjutnya setelah validasi dilakukan penyebaran kuesioner kepada responden. Dari 70 kuesioner, hanya 50 yang terkumpul dan ditabulasikan.

\section{Uji validitas dan reliabilitas}

Suatu instrumen pengukuran dapat dikatakan mempunyai validitas tinggi apabila alat tersebut memberikan hasil pengukuran yang sesuai dengan tujuan pengukuran tersebut. Uji Validitas.

Untuk mengetahui kuesioner tersebut valid atau tidak, peneliti harus melakukan Uji Validitas menggunakan program SPSS for windows. Untuk bisa dinyatakan Valid maka $\mathrm{R}$ hitung > R tabel, dengan signifikansi 0,05 maka harus melebihi Rtabel dengan Rtabel responden 50 adalah 0,279 , maka setiap variabel nya dikatakan valid jika $>0,279$.

Hasil pengujian Validitas, terdapat 2 variabel tidak valid.

Instrumen dinyatakan reliabel atau andal apabila menghasilkan ukuran yang konsisten walaupun digunakan untuk mengukur berkalikali.

\begin{tabular}{|r|r|}
\hline $\begin{array}{c}\text { Cronbach's } \\
\text { Alpha }\end{array}$ & N of Items \\
\hline, 951 & 48 \\
\hline
\end{tabular}

Gambar 4. Reliability Statistics

Sumber: Analisis Penulis, 2019

Hasil menunjukkan nilai Cronbach alpha sebesar 0,951 yang menunjukkan bahwa kuesioner penelitian memiliki faktor reliabilitas yang tinggi.

\section{Analisis peringkat menggunakan Mean Rank}

Sampel data yang masing-masing berupa frekuensi pada setiap variabel yang 
merupakan hasil pengisian responden, menjadi input analisis dengan metode analisis deskriptif yang dimulai dengan menjumlahkan skor kuesioner yang telah diisi oleh responden menggunakan skala Likert, kemudian menghitung nilai standar deviasi.

Standar deviasi adalah nilai statistik yang digunakan untuk menentukan bagaimana sebaran data dalam sampel, dan seberapa dekat titik data individu ke mean atau ratarata nilai sampel. Jika didapati nilai standar deviasi suatu sampel data sama dengan 0 (nol) maka hal tersebut menunjukkan bahwa semua nilai dalam data tersebut adalah sama. Semakin besar nilai standar deviasi suatu data maka semakin besar jarak setiap titik data dengan nilai rata-rata.

\section{Analisis Rangking Secara Keseluruhan}

Analisis rangking secara keseluruhan memperlihatkan hasil secara umum peringkat semua faktor-faktor keterlambatan penyelesaian proyek konstruksi 6 Ruas Jalan Tol dalam kota Jakarta.

\section{Tabel 1. Hasil Analisis Deskriptif}

\begin{tabular}{cccc}
\hline No. & Variabel & Mean & St.Deviasi \\
\hline $\mathbf{1}$ & X1 & 4,40 & 0,495 \\
\hline $\mathbf{2}$ & X2 & 4,26 & 0,600 \\
\hline $\mathbf{3}$ & $\mathrm{X} 3$ & 4,00 & 0,881 \\
\hline $\mathbf{4}$ & $\mathrm{X} 4$ & 3,96 & 1,212 \\
\hline $\mathbf{5}$ & $\mathrm{X} 5$ & 3,66 & 0,872 \\
\hline $\mathbf{6}$ & $\mathrm{X} 6$ & 4,28 & 0,454 \\
\hline $\mathbf{7}$ & $\mathrm{X} 7$ & 3,94 & 0,767 \\
\hline $\mathbf{8}$ & $\mathrm{X} 8$ & 3,84 & 0,934 \\
\hline $\mathbf{9}$ & $\mathrm{X} 9$ & 3,90 & 0,995 \\
\hline $\mathbf{1 0}$ & $\mathrm{X} 10$ & 3,40 & 0,833 \\
\hline $\mathbf{1 1}$ & $\mathrm{X} 11$ & 4,28 & 0,927 \\
\hline $\mathbf{1 2}$ & $\mathrm{X} 12$ & 4,58 & 0,785 \\
\hline $\mathbf{1 3}$ & $\mathrm{X} 13$ & 3,48 & 0,931 \\
\hline $\mathbf{1 4}$ & $\mathrm{X} 14$ & 4,34 & 0,658 \\
\hline $\mathbf{1 5}$ & $\mathrm{X} 15$ & 3,58 & 0,859 \\
\hline $\mathbf{1 6}$ & $\mathrm{X} 16$ & 3,64 & 0,985 \\
\hline $\mathbf{1 7}$ & $\mathrm{X} 17$ & 3,42 & 0,950 \\
\hline
\end{tabular}

\begin{tabular}{|c|c|c|c|}
\hline 18 & X18 & 3,36 & 0,827 \\
\hline 19 & X19 & 3,92 & 0,778 \\
\hline 20 & $\mathrm{X} 20$ & 4,10 & 0,647 \\
\hline 21 & $\mathrm{X} 21$ & 4,26 & 0,664 \\
\hline 22 & $\mathrm{X} 22$ & 3,98 & 0,622 \\
\hline 23 & $\mathrm{X} 23$ & 3,86 & 1,030 \\
\hline 24 & $\mathrm{X} 24$ & 4,08 & 0,986 \\
\hline 25 & X25 & 3,98 & 0,915 \\
\hline 26 & $\mathrm{X} 26$ & 3,60 & 0,782 \\
\hline 27 & $\mathrm{X} 27$ & 3,84 & 0,997 \\
\hline 28 & X28 & 4,16 & 0,738 \\
\hline 29 & X29 & 3,44 & 0,884 \\
\hline 30 & X30 & 4,24 & 0,591 \\
\hline 31 & X31 & 3,90 & 0,931 \\
\hline 32 & X32 & 3,92 & 1,027 \\
\hline 33 & X33 & 3,80 & 0,857 \\
\hline 34 & X34 & 3,68 & 0,868 \\
\hline 35 & X35 & 4,02 & 0,892 \\
\hline 36 & X36 & 2,96 & 1,029 \\
\hline 37 & X37 & 3,50 & 0,863 \\
\hline 38 & X38 & 3,56 & 0,993 \\
\hline 39 & X39 & 3,90 & 1,074 \\
\hline 40 & $\mathrm{X} 40$ & 3,82 & 0,896 \\
\hline 41 & $\mathrm{X} 41$ & 4,06 & 0,767 \\
\hline 42 & $\mathrm{X} 42$ & 4,06 & 0,935 \\
\hline 43 & $\mathrm{X} 43$ & 4,34 & 0,872 \\
\hline 44 & $\mathrm{X} 44$ & 3,28 & 0,858 \\
\hline 45 & $\mathrm{X} 45$ & 3,82 & 0,691 \\
\hline 46 & $\mathrm{X} 46$ & 3,44 & 1,128 \\
\hline 47 & $\mathrm{X} 48$ & 3,76 & 1,188 \\
\hline 48 & X50 & 3,40 & 1,309 \\
\hline
\end{tabular}

Sumber: Analisis Penulis, 2019

\section{Analisis Rangking 10 (sepuluh) Terbesar}

Analisis rangking 10 (sepuluh) terbesar menunjukkan 10 (sepuluh) terbesar faktor penyebab keterlambatan proyek pembangunan 6 Ruas Jalan tol dalam Kota Jakarta. 
Tabel 2. Rangking Faktor Sepuluh Terbesar

\begin{tabular}{ccccc}
\hline No. & Kode & Mean & Std. Deviasi & Rank \\
\hline $\mathbf{1}$ & X12 & 4,58 & 0,785 & 1 \\
\hline $\mathbf{2}$ & X1 & 4,40 & 0,495 & 2 \\
\hline $\mathbf{3}$ & X14 & 4,34 & 0,658 & 3 \\
\hline $\mathbf{4}$ & X43 & 4,34 & 0,872 & 4 \\
\hline $\mathbf{5}$ & X6 & 4,28 & 0,454 & 5 \\
\hline $\mathbf{6}$ & X11 & 4,28 & 0,927 & 6 \\
\hline $\mathbf{7}$ & X2 & 4,26 & 0,600 & 7 \\
\hline $\mathbf{8}$ & X21 & 4,26 & 0,664 & 8 \\
\hline $\mathbf{9}$ & X30 & 4,24 & 0,591 & 9 \\
\hline $\mathbf{1 0}$ & X28 & 4,16 & 0,738 & 10 \\
\hline & $\mathrm{N}=50$ & & &
\end{tabular}

Sumber: Analisis Penulis, 2019

\section{Kesimpulan}

Berkaitan dengan rumusan masalah, tujuan, dan tahapan-tahapan proses penelitian mengenai Studi Faktor Penyebab Keterlambatan Proyek Kontruksi Pada Pembangunan 6 Ruas Jalan Tol dalam Kota Jakarta, dapat diambil kesimpulan sebagai berikut :

a. Indikator dengan nilai mean tertinggi dan terendah adalah:

1) (X12) Tahap pengerjaan kegiatan tidak sesuai dengan jadwal yang direncanakan, dengan nilai mean sebesar 4,58 dan nilai standar deviasi 0,785

2) (X28) Telatnya pembayaran pada pekerja, dengan nilai mean sebesar 4,16 dan nilai standar deviasi 0,738

b. Antisipasi dan Solusi Penyebab Keterlambatan :

1) Faktor (X12) Tahap pengerjaan kegiatan tidak sesuai dengan jadwal yang direncanakan.

- Antisipasi : Melakukan koordinasi pekerjaan lain yang bisa dikerjakan terlebih dahulu agar meminimalisir terjadinya keterlambatan.

- Solusi : Pekerjaan yang dilakukan harus diprioritaskan agar berdampak positif pada hasil proyek dan tidak merugikan kedua belah pihak

2) Faktor (X1) Keterlambatan pengiriman bahan.

- Antisipasi : Disediakannya jalur khusus kendaraan proyek.

- Solusi : Harus adanya kontraktor yang memadai dalam segi financial yang bisa diandalkan untuk menunjang kelengkapan bahan ditempat pekerjaan

3) Faktor (X14) Pengaruh lalu lintas didaerah sekitar proyek

- Antisipasi : Disediakannya jalur alternatif kendaraan umum untuk mengurangi kemacetan panjang.

- Solusi : Memperbaiki manajemen lalu lintas sekitar proyek

4) Faktor (X43) Kenaikan harga BBM

- Antisipasi : Merencanakan / menggunakan pembelian BBM yang mahal.

- Solusi : Dilakukan pemeriksaan / maintenance peralatan secara berkala, atau bisa dengan menggunakan bahan tambah seperti Eco Racing.

5) Faktor (X6) Kurangnya keahlian tenaga kerja

- Antisipasi : Pada saat penerimaan tenaga kerja harus diadakan tes yang sesuai kebutuhan pada proyek, dan memberikan pelatihan terhadap tenaga kerja.

- Solusi : Mengganti tenaga kerja ahli dengan yang lebih berpengalaman.

\section{Daftar Pustaka}

Andi Maddeppungeng, Rahman Abdullah, Deden Matri Wirabakti (2013) "Studi Faktor-Faktor Penyebab Keterlambatan Proyek Konstruksi : Universitas Sultan Ageng Tirtayasa.

Andy Putra Rambe (2018) "Analisis Faktor Penyebab Keterlambatan Proyek 
Konstruksi Jalan Tol" Medan : Universitas Sumatra Utara.

Baehaki, dkk (2018) "Dokumen Pedoman Penulisan dan Penyusunan Tugas Akhir/Skripsi" Cilegon : Universitas Sultan Ageng Tirtayasa

Baiq Farida Sakinah (2015) "Analisis Penyebab Keterlambatan Pada Pekerjaan Konstruksi Jalan Kabupaten Lombok Tengah Dengan Metode Analisis Faktor" Malang : Universitas Brawijaya

Haekal Hassan (2016) "Faktor-Faktor Penyebab Keterlambatan Pada Proyek Konstruksi Dan Alternatif Penyelesaiannya (Studi Kasus : Manado Town Square Iii)" Manado : Universitas Sam Ratulangi Manado

Hasoloan Benget Sianipar (2012) "Analisis Faktor-Faktor Penyebab Keterlambatan Penyelesaian Proyek Konstruksi Pengaruhnya Terhadap Biaya" Surakarta Herdi Alif Al Hikam (2019, 4 Januari) mengintip progres tol layang dki rute kelapa gading-pulo gebang.detikfinance.

Imay Zulkasa, Budiono, Budi Arief (2016)

"Percepatan Pelaksanaan Pekerjaan Proyek Jalan Serua Raya Depok Dengan Metode Time Cost Trade Off" Jakarta Jalan tol layang dalam kota jakarta (2019, 5 Februari)wikipedia

Mochtar Sibi (2015) "Identifikasi FaktorFaktor Cost Overrun Biaya Overhead Pada Proyek Pembangunan Manado Town Square III" Manado

Oktya Putri Cahya Ardika, Sugiyarto, Fajar Sri Handayani (2014) "Analisis Time Cost Trade Off Dengan Penambahan Jam Kerja pada Proyek Konstruksi" Surakarta

Ruslan Ramang, John. H. Frans, Putri D.K (2017) "Faktor-Faktor Keterlambatan Proyek Jalan Raya Di Kota Kupang Berdasarkan Persepsi Stakeholder" Kupang

Rizky Widyo Kisworo, Fajar Sri Handayani, Sunarmasto (2017) "Analisis Percepatan Proyek Menggunakan Metode Time Cost
Trade Off Dengan Penambahan Jam kerja Lembur dan Jumlah Alat" Surakarta Undang-Undang No.2 Tahun 2017 Tentang "Jasa Konstruksi"

Peraturan Presiden Republik Indonesia Nomor 70 Tahun 2012 tentang “Pengadaan Barang/Jasa Pemerintah". 
